\title{
Diagnosis of Large Papillary Excavations in Developing Countries: From Automated Visual Field to OCT of the Ganglion Complex. About a Case
}

\author{
Kokou Messan Amedome ${ }^{1 *}$, Kassoula Batomaguéla Nonon Saa², Kossi Dzidzinyo², \\ Kokou Vonor ${ }^{3}$, Nidain Maneh${ }^{4}$, Koffi Didier Ayena ${ }^{5}$, Komi Balo ${ }^{2}$ \\ ${ }^{1}$ Centre Hospitalier Universitaire de Kara, Kara, Togo \\ ${ }^{2}$ Centre Hospitalier Universitaire Sylvanus Olympio de Lomé, Lomé, Togo \\ ${ }^{3}$ Centre Hospitalier Régional de Kara Tomdè, Kara, Togo \\ ${ }^{4}$ Centre Hospitalier Universitaire Campus de Lomé, Lomé, Togo \\ ${ }^{5}$ Hôpital de Bè Lomé, Lomé, Togo \\ Email: *amedomekokoumessan@gmail.com
}

How to cite this paper: Amedome, K.M. Saa, K.B.N., Dzidzinyo, K., Vonor, K., Maneh, N., Ayena, K.D. and Balo, K. (2021) Diagnosis of Large Papillary Excavations in Developing Countries: From Automated Visual Field to OCT of the Ganglion Complex. About a Case. Open Journal of Ophthalmology, 11, 143-151.

https://doi.org/10.4236/ojoph.2021.112011

Received: March 9, 2021

Accepted: May 25, 2021

Published: May 28, 2021

Copyright $\odot 2021$ by author(s) and Scientific Research Publishing Inc. This work is licensed under the Creative Commons Attribution International License (CC BY 4.0).

http://creativecommons.org/licenses/by/4.0/

\begin{abstract}
Background: Large papillary excavations constitute a true differential diagnosis of glaucoma in our environments. Aim: To present a clinical case of large papillary excavation simulating glaucomatous optic neuropathy in a young subject. Case Presentation: The ophthalmologic examination made it possible to note a visual acuity of LogMar 0.00 , ocular hypertonia and a large papillary excavation in both eyes. The visual field noted bilateral perimetric involvement suggesting optic neuropathy. Optical coherence tomography (OCT) of the ganglion complex revealed an absence of involvement of the ganglion complex and the ganglion ridge essential to evoke optic neuropathy. An ocular hypotonizing treatment made it possible to normalize the intraocular pressure. Conclusion: The particularity of this observation lies in the fact that the perimeter involvement that preceded any involvement can simulate a glaucomatous involvement. Functional damage to the visual field must be correlated with structural damage to suggest glaucomatous damage in our ophthalmic patients.
\end{abstract}

\section{Keywords}

Large Excavation, Optic Neuropathy, Glaucoma, OCT, Kara

\section{Introduction}

Papillary excavation is the depression seen in the center of the papilla or head of 
the optic nerve. It is sometimes non-existent in a small papilla; or, conversely, large and cylindrical in the case of a large papilla [1] where they can be round or with a large horizontal axis: it's the large physiological excavation. In its modern definition, glaucoma is a progressive optic neuropathy manifested by abnormalities of the optic papilla and subsequent alterations in the visual field [2]. Glaucoma is currently the leading cause of irreversible blindness worldwide [3]. Very globally, based on data from a meta-analysis published in 2006, the prevalence of POAG is higher in the black population, intermediate in Caucasians and Hispanics, and low in some Asian populations. We thus find $2.1 \%$ for the Caucasian population, $4.2 \%$ for the black population and $1.4 \%$ for the Asian population [4]. Among blacks, the prevalence of POAG is higher: 3.90\% in the African Caribbean Eye Survey carried out in England [5], 4.74\% in the Baltimore Eye Survey [6], and up to 7\% in the Barbados Eye Study (Caribbean) [7]. Glaucomatous alterations are thus constituted by a progression of the papillary excavation with a characteristic appearance, a deficit in the visual field survey reflecting the attack of the ganglion cells highlighted on tomography in optical coherence. In general, the optic disc cup area is increased in glaucomatous eyes, and the cup-to-disc ratio is used for diagnosing glaucoma [8]. However, the cup area is also large in eyes with a large optic disc, and these eyes may not be glaucomatous [9] [10]. Therefore, a careful examination is needed to discriminate whether a large cup area is due to glaucoma or to a large optic disc. Large papillary excavations therefore constitute a differential diagnosis of large glaucomatous excavation in our settings, thus forcing the clinician to resort to more advanced paraclinical examinations in order to make the diagnosis. Through this observation, we present a case of large excavation with the perimeter survey of lesions simulating from the outset an optic neuropathy. The OCT noted an absence of lymph node cell involvement, thus confirming that this is a large physiological papillary excavation.

\section{Case Presentation}

Our clinical observation concerned a patient L.K.D. 41 years old, a magistrate who consulted in ophthalmology in the University Teaching Hospital of Kara in Togo for ocular pain localized on the right side radiating to the head and recently appeared 48 hours before the consultation. In terms of history, there was no known personal, medical or surgical antecedent. There was no ophthalmologic antecedent. On clinical ophthalmologic examination, there was no anomaly in the eye appendages and no pain on palpation of the orbital rim. The visual acuity was LogMar 0.00 . The autorefractometry was $+0.00 ;-0.25 ; 15^{\circ}$ at the right eye and $+0.12 ;-0.25 ; 140^{\circ}$ at the left eye. The eye pressure was $28 \mathrm{mmhg}$ in the right eye and $32 \mathrm{mmhg}$ in the left eye. With the slit lamp, the cornea is quite transparent, the anterior chamber of the eyeball is calm. The iris texture, the pupil and the lens show no abnormalities. The direct and consensual photomotor reflex is normal. The pupillary glow was normal. On examination of the fundus in pupillary dilation, we note an excavated papilla at 0.6 the macular reflection is nor- 
mal, there was no abnormality in the retinal field. At the end of the clinical examination, a hypothesis of optic neuropathy was suggested and an automated visual field considered. On the perimeter reading as can be seen in Figure 1, there is an extensive paracentral deficit in the lower and upper parts of the right eye without involvement of the central fixation point. In the left eye, there is a concentric narrowing of the visual field. Faced with these almost characteristic deficits, an optic neuropathy hypothesis no doubt appeared. Admittedly, an OCT of the ganglion complex was requested. This examination, carried out as shown in Figure 2, made it possible to note: a good symmetry of the RNFL layer at $94 \%$, a large vertical papillary excavation measured at 0.64 on the right and 0.67 on the left. The surface of the neuroretinal ring is normal. No involvement of the peripapillary or perimacular fibers. No involvement of the ganglion complex or the ganglionic ridge.

In short, the optic neuropathy hypothesis therefore leaves room for the hypothesis of a large physiological papillary excavation associated with ocular hypertension.

Immediate management consisted of the use of a local and systemic hypotonizer and a systemic analgesic. By local route, we had used latanoprost eye drops $0.005 \%$ which is an analogue of prostaglandin at the rate of an instillation in the evening which we had associated with a beta-blocker in eye drops which is timolol $0.5 \%$ at a rate of one instillation morning and evening. Systemically, we used acetazolamide tablet which is a carbonic anhydrase inhibitor $250 \mathrm{mg}$ morning and evening for one week. The analgesic treatment consisted of the use of paracetamol at a rate of $1 \mathrm{~g}$ every 8 hours for 72 hours. After one week of treatment, the evolution was marked by a regression of eye pain and headache with normalization of intraocular pressure which went from $28 \mathrm{mmhg}$ on the right to $13 \mathrm{mmhg}$ and on the left from $32 \mathrm{mmhg}$ to 14 mmhg. The patient kept a monotherapy based on $0.5 \%$ timolol eye drops after 2 weeks of this triple therapy.

\section{Discussion}

The discovery of an excavation, even a large one, does not therefore mean that the papilla is damaged.

For the black race, a 9-year follow-up was proposed by the Barbados Eye Study, including 3222 subjects, and estimated the incidence of POAG at $4.4 \%$, or $0.49 \%$ per year [11]. The Collaborative Glaucoma Study reported that in subjects over 60 years of age, the incidence of open-angle glaucoma was 7 times higher than in subjects under 40 years [12].

On the ophthalmoscopic observation of 6750 papillae, Witusik [13] in the journal Ophtalmologica had noted that on $78 \%$ of excavations, half of them being qualified as "medium" or "large" and, 4 times out of 10, the riddled slide was visible at the bottom of these physiological excavations. Armaly for his part, in the Archives of Ophthalmology [14] described for the first time the C/D ratio 


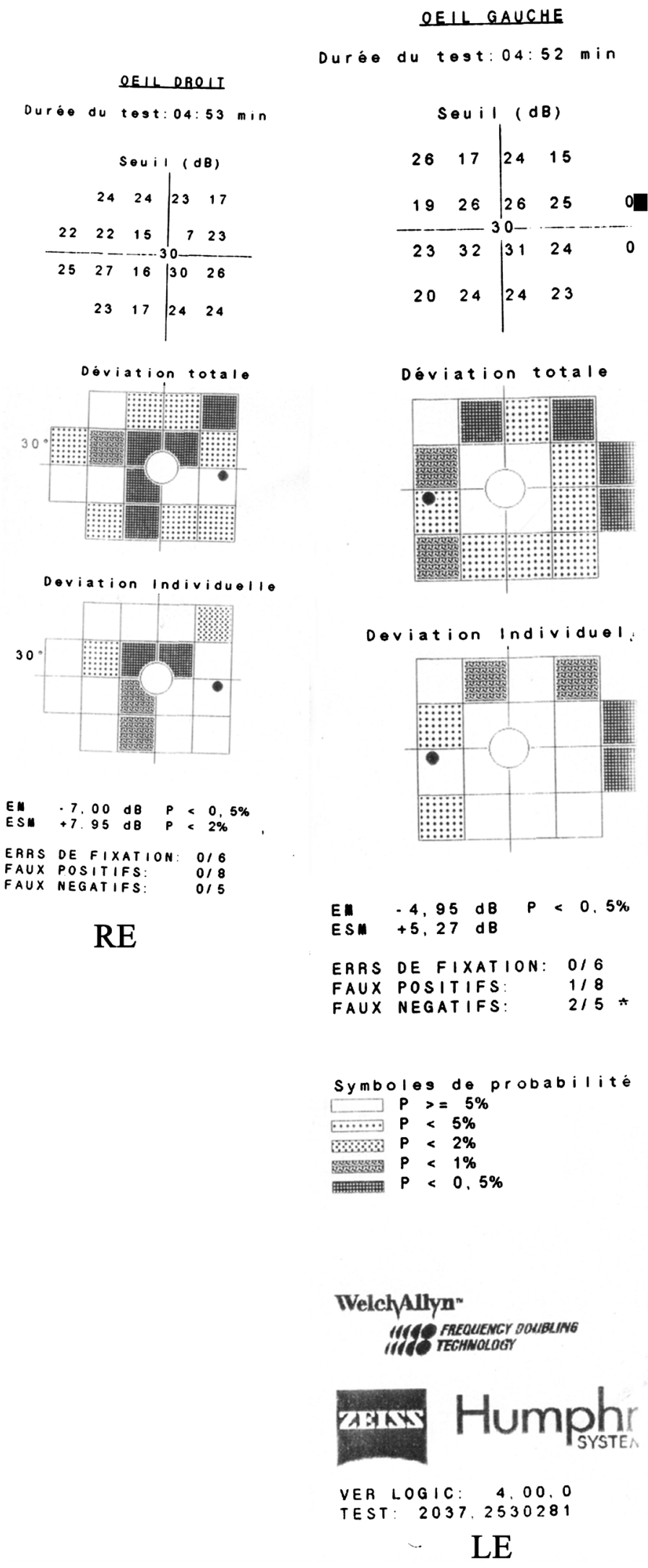

Figure 1. Automated visual field: RE: superior and inferior paracentral scotoma without involvement of the fixation point; LE: concentric narrowing of the visual field. 


\begin{tabular}{llllll} 
& & & OD & OS & \\
ID: & CZMI618226904 & Date d'examen: & $04 / 12 / 2020$ & $04 / 12 / 2020$ & CZM \\
Date de naissance: & 02/12/1979 & Heure de l'examen: & $11: 59$ & $12: 00$ & \\
Sexe: & Masculin & Numéro de série: & $4000-2319$ & $4000-2319$ & \\
Technicien : Operateur, CIRRUS & Puissance du signal: & $7 / 10$ & $8 / 10$ & \\
\hline
\end{tabular}

\section{RNFL et ONH :Optic Disc Cube 200x200}

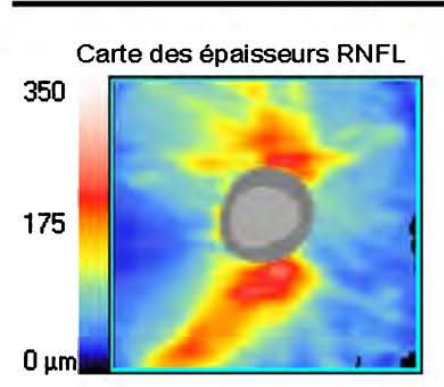

Carte des écarts RNFL

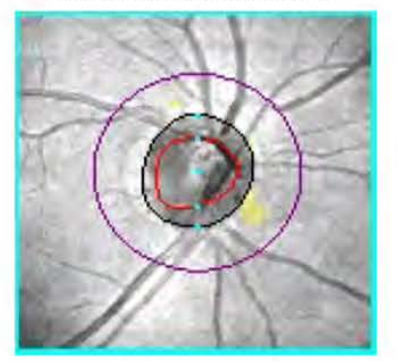

Centre du disque $(0,00,0,21) \mathrm{mm}$ Tomographie horizontale extraite

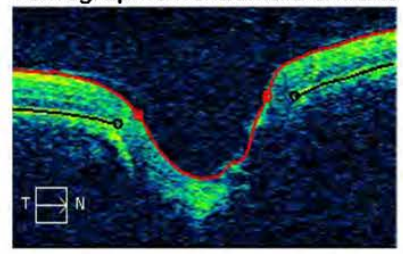

Tomographie verticale extraite

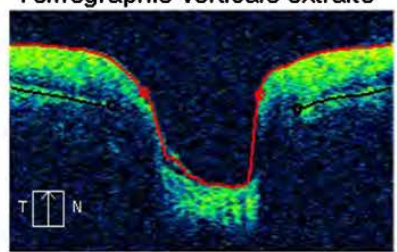

Tomographie circulaire RNFL

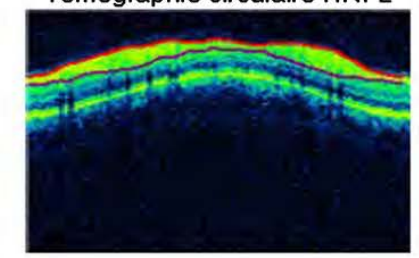

\begin{tabular}{|r|c|c|}
\hline \multicolumn{1}{|c|}{ OD } & OS \\
\hline Épaisseur moyenne RNFL & $114 \mu \mathrm{m}$ & $117 \mu \mathrm{m}$ \\
\hline Symétrie RNFL & \multicolumn{2}{|c|}{$94 \%$} \\
\hline Aire de l'ANR & $1,47 \mathrm{~mm}^{2}$ & $1,39 \mathrm{~mm}^{2}$ \\
\hline Aire du disque & $2,85 \mathrm{~mm}^{2}$ & $2,75 \mathrm{~mm}^{2}$ \\
\hline Rapport CD moyen & 0,69 & 0,70 \\
\hline Rapport CD vertical & 0,64 & 0,67 \\
\hline Volume de l'excavation & $0,707 \mathrm{~mm}^{3}$ & $0,783 \mathrm{~mm}^{3}$ \\
\hline
\end{tabular}

Épaisseur du bord de la neurorétine

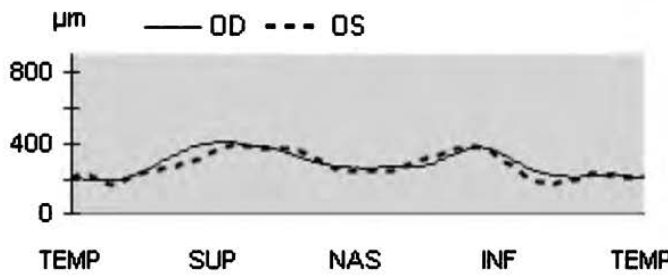

Épaisseur RNFL
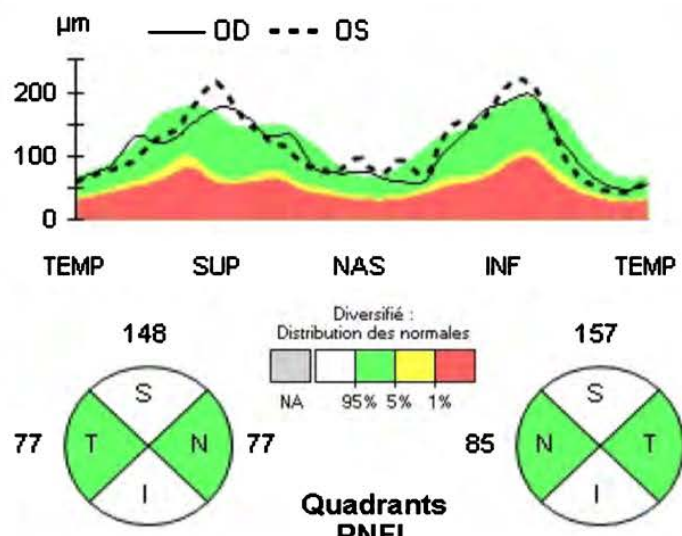

153

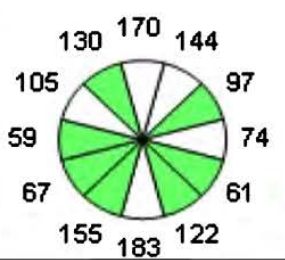

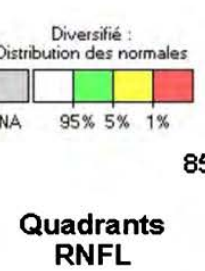
RNFL

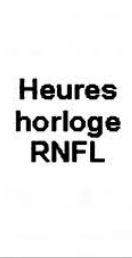

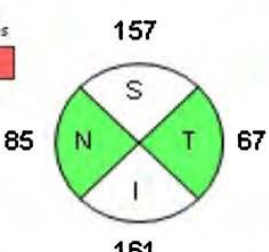

161

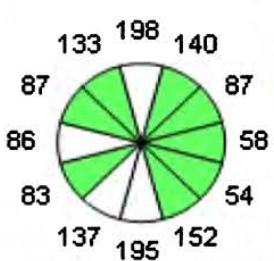
OD O O OS

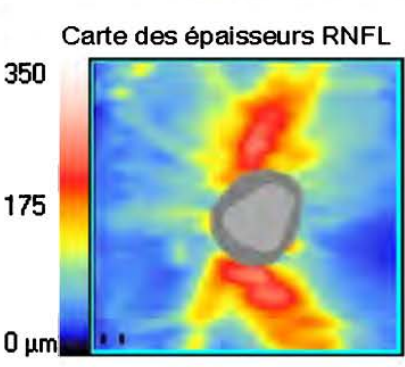

Carte des écarts RNFL

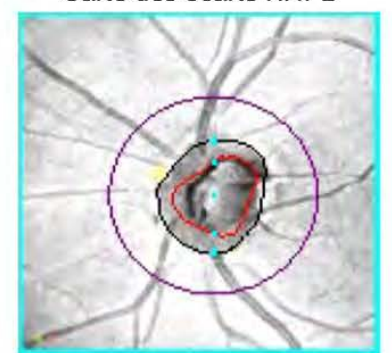

Centre du disque $(0,21,-0,18) \mathrm{mm}$ Tomographie horizontale extraite

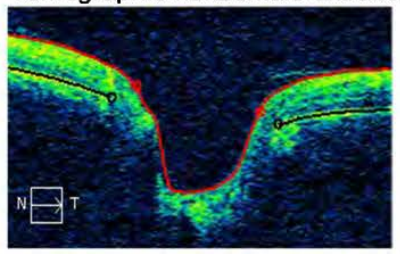

Tomographie verticale extraite

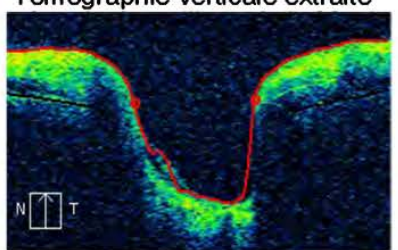

Tomographie circulaire RNFL

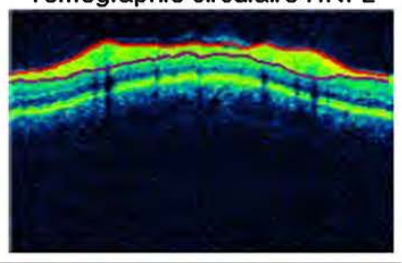

CIRRUS4000

SW Ver: 7.0.3.19

Copyright 2015

Carl Zeiss Meditec, Inc

All Rights Reserved

Page 1 sur 2

(a) 


\begin{tabular}{|c|c|c|c|c|c|c|}
\hline & & & OD & os & & ZEISS \\
\hline ID: & CZMI618226904 & Date d'examen: & $04 M 2 / 2020$ & $04 M 2 / 2020$ & $\operatorname{CDM}$ & \\
\hline Date de naissance: & $02 M 2 M 979$ & Heure de l'examen: & $11: 59$ & $12: 00$ & & \\
\hline Sexe: & Masculin & Numéro de série: & $4000-2319$ & $4000-2319$ & & \\
\hline \multicolumn{2}{|c|}{ Technicien: Operateur, CIRRUS } & Puissance du signal: & $7 M 0$ & $8 M 0$ & & \\
\hline
\end{tabular}

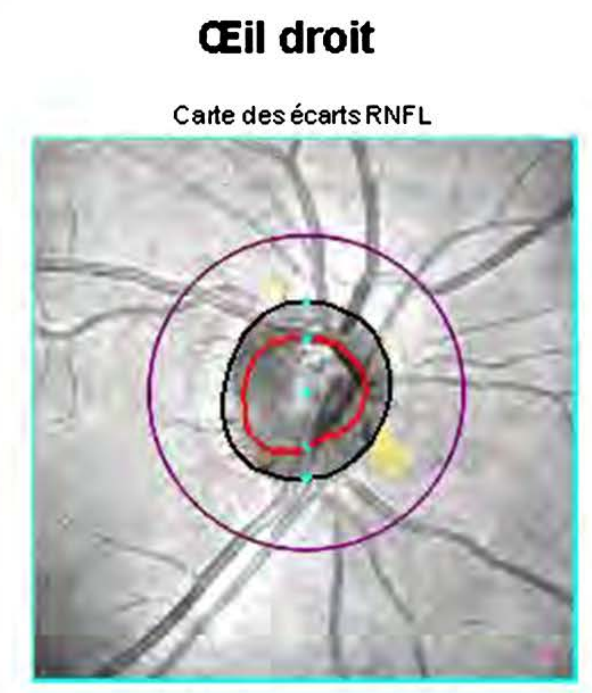

Centre du disque $(0,00,0,21) \mathrm{mm}$

Épaisseur RNFL

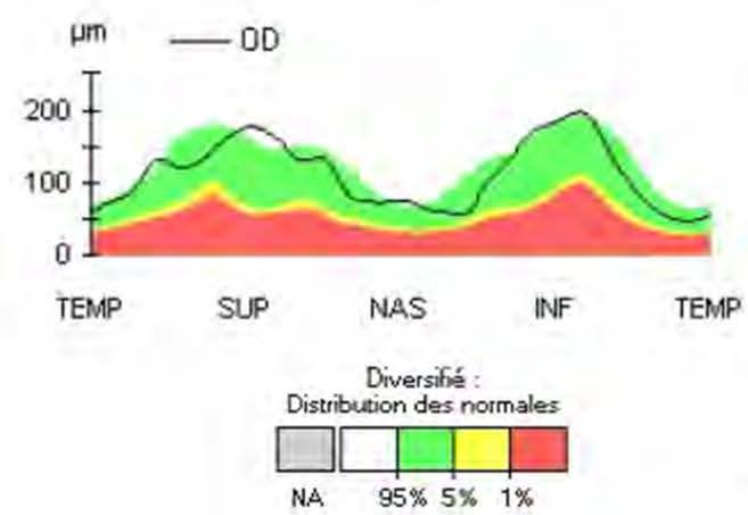

\section{Cil gauche}

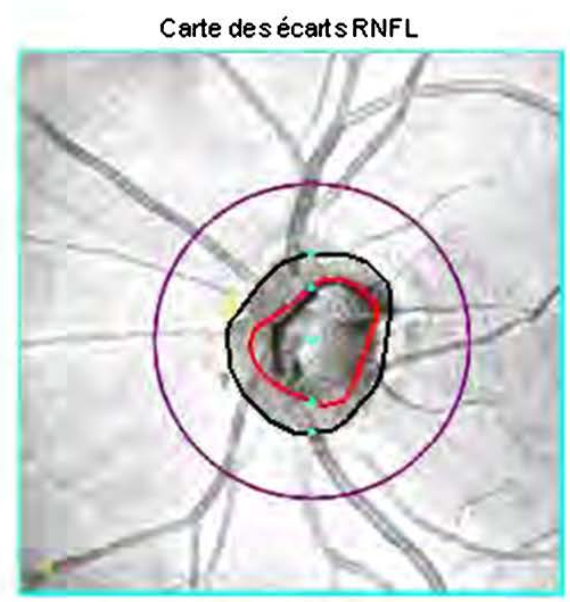

Centre du disque $(0,21,-0,18) \mathrm{mm}$

Ėpaisseur RNFL

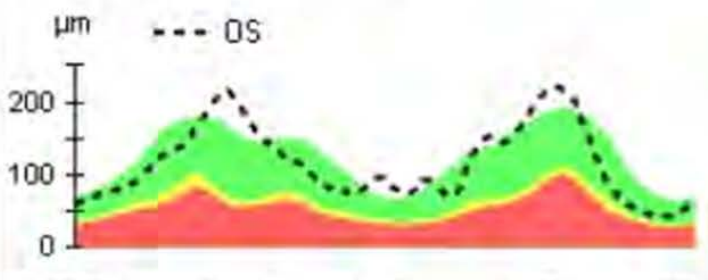

\begin{tabular}{|c|c|c|}
\hline Commentaires & Signature du médecin & $\begin{array}{l}\text { CIRRUS4000 } \\
\text { SW Ver. 7.0.3.19 } \\
\text { Copyright 2015 } \\
\text { Carl Zeiss Meditec, Inc } \\
\text { All Rights Reserved }\end{array}$ \\
\hline & & Page 2 sur 2 \\
\hline
\end{tabular}

(b) 


\begin{tabular}{|c|c|c|c|c|c|c|}
\hline \multirow[b]{2}{*}{ ID: } & & & OD & os & \multirow[b]{2}{*}{ CZM } & \multirow{2}{*}{ ZEISS } \\
\hline & CZMI618226904 & Date d'examen: & $04 / 2 / 2020$ & $04 / 12 / 2020$ & & \\
\hline Date de naissance: & $02 / 12 M 979$ & Heure de l'examen: & $11: 57$ & $12: 01$ & & \\
\hline Sexe: & Masculin & Numéro de série: & $4000-2319$ & $4000-2319$ & & \\
\hline \multicolumn{2}{|c|}{ Technicien: Operateur, aRRUS } & Puissance du signal: & $8 / 10$ & $9 / 10$ & & \\
\hline
\end{tabular}

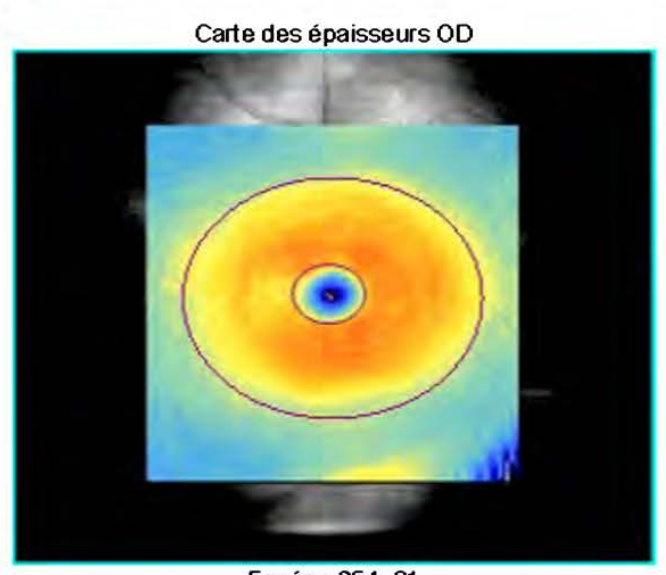

Fovéa : 254, 61
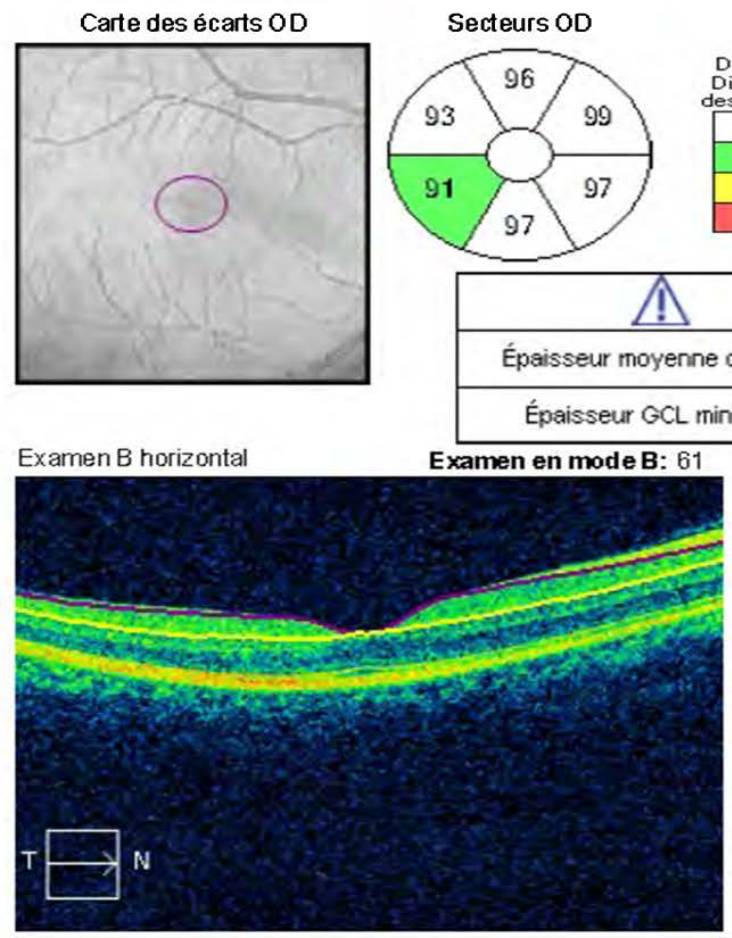

Commentaires

Signature du médecin

Commentaires

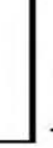

Examen B horizontal
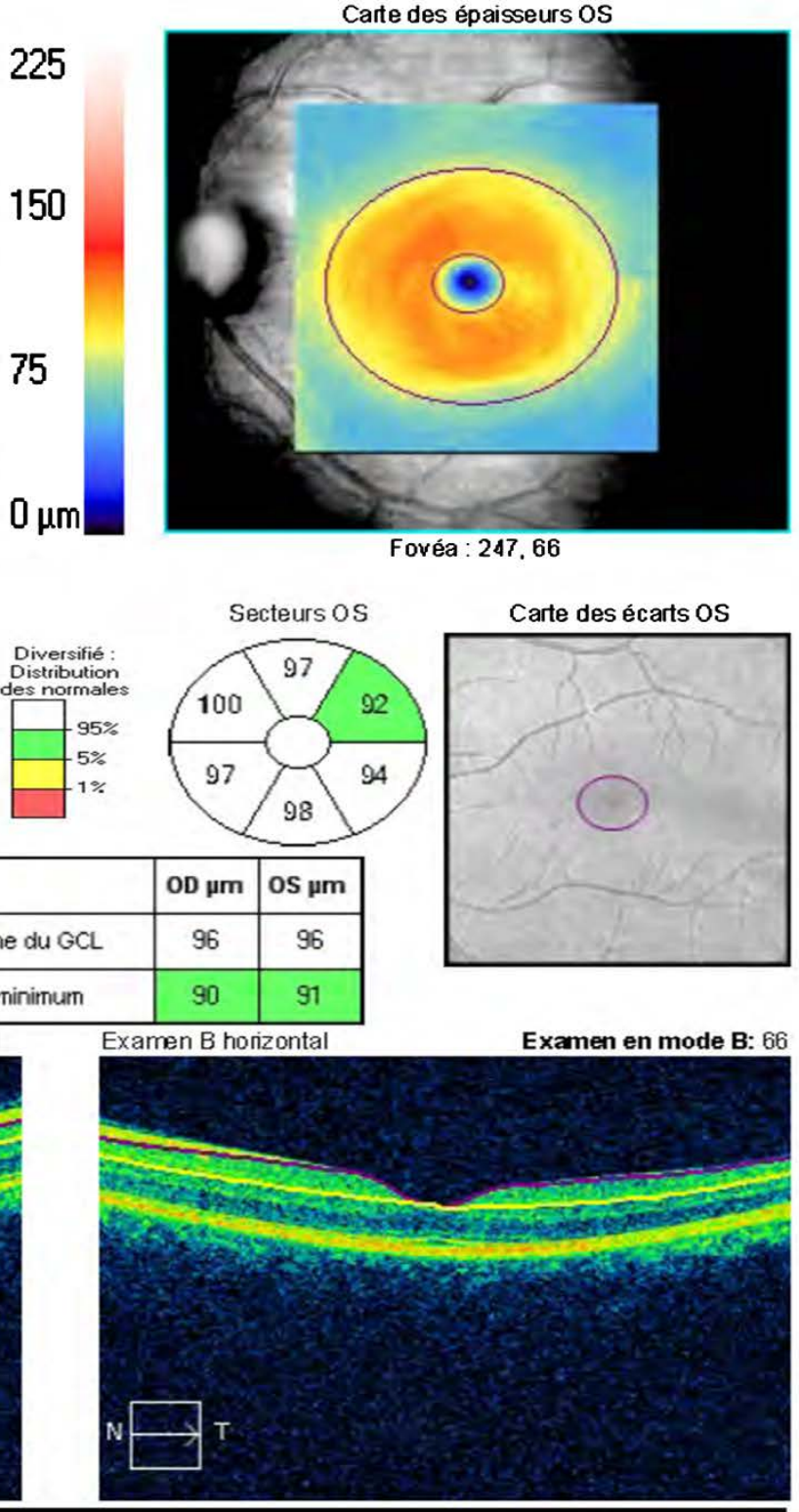

91

CIRRUS4000

SW Ver: 7.0.3.19

Copyright 2015

Carl Zeiss Meditec, Inc

All Rights Reserved

Page 1 sur 1

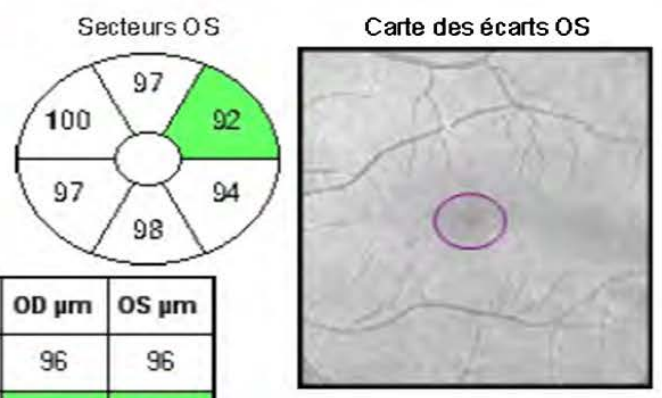

(c)

Figure 2. (a) Ganglion complex OCT: papilla mapping; (b) Ganglion complex OCT: curve of normal RNFL thickness; (c) Ganglion complex OCT: normal thickness. 
and, in this original article studying the fundus of 616 glaucomatous or healthy subjects had found $1 / 3$ of papillae non-glaucomatous with excavation greater than 0.3 , and $6 \%$ with excavation greater than 0.5 .

These results of ancient works are corroborated by all modern works using automated analyzers of the optic nerve head. A racial factor is involved in the size of the disc, in particular melanodermic subjects who have usually larger optic discs therefore also have larger physiological excavations. According to Jonas [15]:

Physiological excavations are usually bilateral and symmetrical. The difference in C/D does not exceed 0.1 in $92 \%$ of cases, 0.2 in 99\% of cases for Armaly. In a more recent and very large study of 3654 individuals (the Blue Mountains Eye Study, 1999), an asymmetry that is 0.2 or more is found in $24 \%$ of glaucomatous subjects $(n=79)$, compared to $1 \%$ of hypertensive subjects. ocular $(n=118)$, and $6 \%$ of normal subjects $(n=2929)$. If physiological differences exist, they are usually due to marked anisometropia. The physiological excavations of large size are located in papillae which are themselves of large size. "Larger the disc, larger the cup" according to Drance. Simple geometric surface measurements thus show that a $2.1 \mathrm{~mm}$ diameter papilla may be the site of an excavation that is 0.8 with a "normal" neuroretinal ring surface. Physiological excavations are usually round or with a large horizontal axis. The neuroretinal ring is usually wider in its lower portion, where the slope of the excavation is smoother, or at least not narrower at the bottom than at the top. The physiological excavation does not change throughout life. They are finally family-oriented, and examination of other family members may be helpful in supporting a diagnosis of physiological excavation.

\section{Conclusion}

A large papillary excavation is not necessarily pathological. On the one hand, the clinical characteristics of this papilla associated with data from analyzers of the optic nerve head in this case are an essential tool for making the diagnosis.

\section{Conflicts of Interest}

The authors declare no conflicts of interest regarding the publication of this paper.

\section{References}

[1] Sellem, E. (2007) La papille: Les point-clé de la clinique. Journal Francais d'Ophtalmologie, 30, 3S47-3S51. https://doi.org/10.1016/S0181-5512(07)89652-5

[2] Spaeth, G.L. (2009) Definitions: What Is Glaucoma Worldwide? Elsevier, I, 293-306.

[3] Khurana, D.A.K. (2007) Comprehensive Ophthalmology. Royal Tunbridge Wells, England: Anshan.

[4] Rudnicka, A.R., Mt-Isa, S., Owen, C.G., Cook, D.G. and Ashby, D. (2006) Variations in Primary Open-Angle Glaucoma Prevalence by Age, Gender, and Race: A Bayesian Meta-Analysis. Investigative Ophthalmology \& Visual Science, 47, 4254-4261. 
https://doi.org/10.1167/iovs.06-0299

[5] Wormald, R.P., Basauri, E., Wright, L.A. and Evans, J.R. (1994) The African Caribbean Eye Survey: Risk Factors for Glaucoma in A Sample of African Caribbean People Living in London. Eye, 8, 315-320.

https://doi.org/10.1038/eye.1994.64

[6] Tielsch, J.M., Sommer, A., Katz, J., Royall, R.M., Quigley, H.A. and Javitt, J. (1991) Racial Variations in the Prevalence of Primary Open-Angle Glaucoma. The Baltimore Eye Survey. Journal of the American Medical Association, 266, 369-374. https://doi.org/10.1001/jama.1991.03470030069026

[7] Leske, M.C., Connell, A.M., Schachat, A.P. and Hyman, L. (1994) The Barbados Eye Study. Prevalence of Open Angle Glaucoma. Archives of Ophthalmology, 112, 821-829. https://doi.org/10.1001/archopht.1994.01090180121046

[8] Foster, P.J., Buhrmann, R., Quigley, H.A. and Johnson, G.J. (2002) The Definition and Classification of Glaucoma in Prevalence Surveys. British Journal of Ophthalmology, 86, 238-242. https://doi.org/10.1136/bjo.86.2.238

[9] Hoffmann, E.M., Zangwill, L.M., Crowston, J.G. and Weinreb, R.N. (2007) Optic Disk Size and Glaucoma. Survey of Ophthalmology, 52, 32-49.

https://doi.org/10.1016/j.survophthal.2006.10.002

[10] Onmez, F.E., Satana, B., Altan, C., Basarir, B. and Demirok, A. (2014) A Comparison of Optic Nerve Head Topographic Measurements by Stratus OCT in Patients with Macrodiscs and Normal-Sized Healthy Discs. Journal of Glaucoma, 23, e152-156. https://doi.org/10.1097/IJG.0000000000000021

[11] Leske, M.C. (2007) Open-Angle Glaucoma-An Epidemiologic Overview. Ophthalmic Epidemiology, 14, 166-172. https://doi.org/10.1080/09286580701501931

[12] Armaly, M.F., Krueger, D.E., Maunder, L., Becker, B., Hetherington, J., Kolker Jr., A.E., Levene, R.Z., Maumenee, A.E., Pollack, I.P. and Shaffer, R.N. (1980) Biostatistical Analysis of the Collaborative Glaucoma Study. I. Summary Report of the Risk Factors for Glaucomatous Visual-Field Defects. Archives of Ophthalmology, 98, 2163-2171. https://doi.org/10.1001/archopht.1980.01020041015002

[13] Witusik, W. (1966) Types of Physiological Cup of the Disc. Ophthalmologica, 152, 57-67. https://doi.org/10.1159/000304954

[14] Armaly, M.F. (1967) Genetic Determination of Cup/Disc Ratio of the Optic Nerve. Archives of Ophthalmology, 78, 35-43. https://doi.org/10.1001/archopht.1967.00980030037007

[15] Jonas, J.B., Guseck, G.C. and Naumann, G.O.H. (1988) Optic Disc, Cup and Neuro-Retinal Rim Size, Configuration and Correlations in Normal Eyes. Investigative Ophthalmology \& Visual Science, 29, 1151-1158. 